\title{
A hybrid analysis procedure enabling elastic design rule assessment of monoblock-type divertor components.
}

\author{
M Fursdon ${ }^{1}, \mathrm{~J}-\mathrm{H}$ You $^{2}, \mathrm{~T}$ Barrett ${ }^{1}, \mathrm{M} \mathrm{Li}^{2}$ \\ 1 CCFE, Culham Science Centre, Abingdon, OX14 3DB, UK, \\ 2 Max-Planck-Institut für Plasmaphysik, Boltzmannstr. 2, 85748 Garching, Germany, \\ Email: mike.fursdon@ukaea.uk
}

Keywords: Design code, residual stress, monoblocks, plasma facing components

\begin{abstract}
This paper presents a simplified rule-based elastic analysis procedure (and its rationale) for the structural integrity assessment of the structural pipe component within monoblock divertor plasma facing components (components constructed from a tungsten block with through cooling pipe and copper interlayer). It is first demonstrated that the conventional fully elastic finite element analysis method used in an elastic code rule assessment must be modified when applied to monoblocks to overcome the problems caused by the assembly of multiple materials (with different yield strengths and different coefficients of thermal expansion causing residual stress). This is done by comparing the result of a fully elastic model with a more representative elasto-plastic model incorporating residual stress simulation. The results show that due to the expected high levels of residual stress, the desired elastic modelling of the structural pipe component can only be used to determine cyclic stress range (but not absolute stress), and even then, only if accompanied by elasto-plastic simulation of the non-structural interlayer (to apply the correct levels of differential expansion loads from the tungsten). This mixed elastic-elasto-plastic method is used in the proposed procedure, and applies the elastic code rules employing cyclic stress range, i.e. rules for ratchetting and fatigue. Additional rules for critical heat flux and allowable material temperatures are added. Example results of an assessment using the procedure are also presented for an ITER-like monoblock divertor target component.
\end{abstract}

\section{Introduction}

The plasma facing component (PFC) used in the ITER divertor is based on the "monoblock" construction (Figure 1) comprising tungsten armour block with through $\mathrm{CuCrZr}$ cooling pipe separated by a copper interlayer[6]. The CuCrZr pipe provides both the structural support and the means for cooling the armour layer. This type of PFC is also being considered for the divertor in DEMO (the demonstration fusion power plant), but because loading conditions are expected to be more onerous (with high levels of irradiation and particle flux) new monoblock designs are being investigated [1] (as part of the EUROfusion power plant physics and technology programme). 
Preferably, before undergoing physical testing, new designs would be assessed using Design by Analysis (DBA) methods following a design code. This is usually achieved by subjecting the results of an elastic Finite Element Analysis (FEA) to a set of "elastic" code rules defining allowable stress for each anticipated failure mechanism. However even the most appropriate current code as used by ITER (SDC-IC [2] ) is not ideally suited for assessing PFCs (such as monoblocks) as highlighted in [5] because it is based largely on existing codes for pressure vessels (e.g. ASME [3]) or conventional nuclear installations (RCCMR[4]). Such codes are aimed mainly at thin-walled single material structures, and so are not well suited to the analysis of the multi-material thick-walled construction of the monoblock. Furthermore, monoblock (and most PFC) materials have different coefficients of thermal expansion (CTEs) which cause considerable residual stress following manufacturing joining processes (e.g. when cooling from brazing temperatures). As will be shown in this paper, these stresses are through-thickness stresses and, as such, are not factored into existing elastic design-code methods.

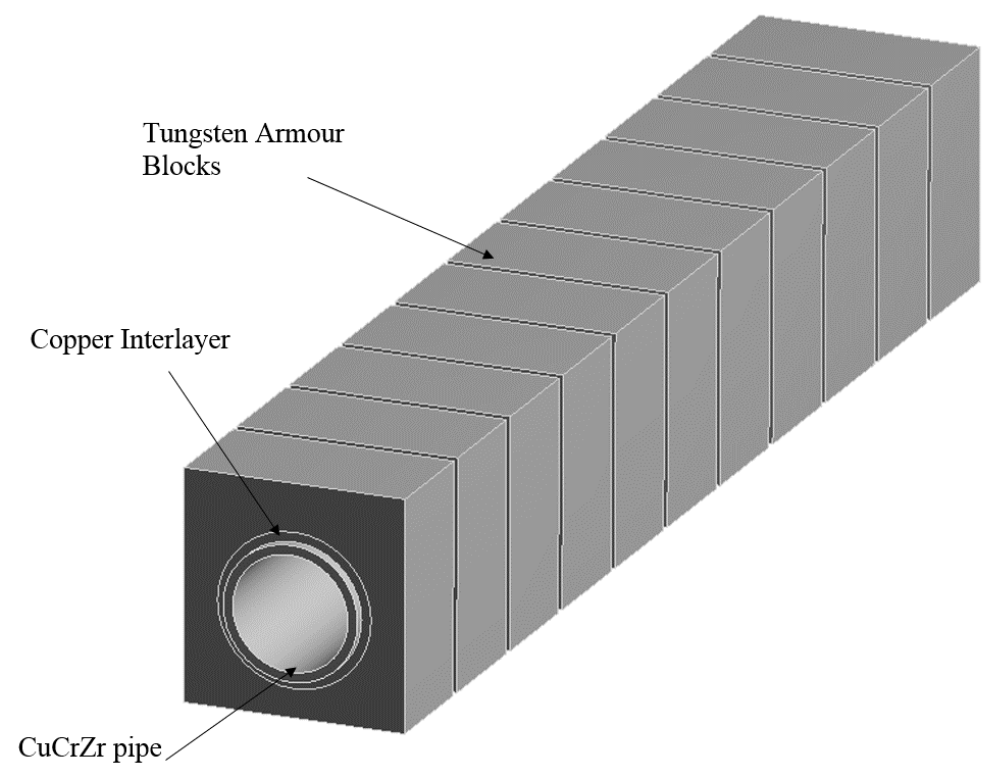

Figure 1 Section from typical divertor plasma facing component comprising a series of individual tungsten armour blocks surrounding a CuCrZr cooling pipe with copper interlayer

ITER currently use both DBA and "design by experiment" methods to overcome the DBA shortfall in their divertor monoblock design assessments [6]. For DEMO, a new (DBA) assessment code is being created to be called the "DEMO Design Criterion" (DDC) based on elasto-plastic FEA methods tailored to PFCs [7]. However, this is not expected to be released in time for the new concepts currently being developed by EUROfusion [8]. To overcome the immediate shortfall, EUROfusion are supporting the development of a "preliminary" analysis procedure specifically for monoblocks (aspects of this procedure are expected to be integrated into the final DDC). This will not only give a 
design "performance" measure to use in design optimisation, but also create a common assessment approach to assess the relative performance of the various design concepts being developed.

This paper describes the first stage of this process in which a simplified monoblock elastic analysis procedure (MEAP) has been created. This procedure aims to give a simple but accurate assessment under steady state normal operating conditions and is based on the existing "elastic" code rules (rules to be used with elastic FE analysis), but in a revised form to suit the monoblock construction. The advantage of elastic rules is that they are simple to apply, are well proven and have considerable status. The disadvantage is that there is no explicit method in the associated elastic FE analysis to incorporate residual stress effects - potentially invalidating the resulting code assessment. In this paper, the validity of the elastic code rule methodology is assessed by making comparisons between an elastic code assessment FE model, and a more accurate full elasto-plastic model of the type devised by $\mathrm{Li}$ and You [24,25]. The latter allows residual stress to be calculated (approximately) which is then carried forward into the analysis of normal operating load steps to give the improved accuracy. From this comparison, a revised set of rules have been formed to create the MEAP.

\section{Scope of Assessment}

\subsection{Load cases}

The divertor in both ITER and the proposed European DEMO fusion power plant, is required to withstand nominal steady state heat loads of the order of $10 \mathrm{MW} / \mathrm{m}^{2}$ during plasma pulses and 20 $\mathrm{MW} / \mathrm{m}^{2}$ during occasional "slow transient" events (estimated to last several seconds) [32][33].In both scenarios steady state heat distribution is achieved. Higher instantaneous heat loads are possible during fast transient major disruption events lasting a few milliseconds [32], but these events tend to affect only the first few mm of the tungsten [31], and are considered outside the scope of this paper. In the following, an assessment is made under the most prevalent operating case of $10 \mathrm{MW} / \mathrm{m}^{2}$. The relevance of the conclusions drawn from this load case to other heat load conditions is discussed in section 4.4 and 7.0. A standby (isothermal) load condition is also considered which, for relevance to DEMO, is set by the anticipated coolant temperature of $150^{\circ} \mathrm{C}$.

\subsection{SDC-IC elastic code assessment}

The rules considered for the MEAP are taken from SDC-IC [2] low temperature rules (section IC3100). The failure mechanisms covered by these rules are plastic collapse, excessive strain (exhaustion ductility, flow localisation), immediate fracture, progressive deformation (ratcheting), and fatigue. The rules within the code are split into those relevant to the first application of the load - the monotonic rules (plastic collapse, excessive-strain, and fracture) - and those relevant to cyclic loading (ratcheting and fatigue). In most cases it is necessary to determine averaged section (membrane) stress or averaged membrane-plus-bending stress (using stress "linearisation") when comparing with allowable stress levels. 
There are also rules in SDC-IC that deal with both elasto-plastic methods and joints (and by implication the effect of joining process). The joint rules are provided primarily for assessing joint strength using knock-down factors (joint coefficients). These rules have not been incorporated into the MEAP, primarily because of a lack of relevant empirical data. The elasto-plastic rules detailed in SDC-IC are also not included in the current work, partly because their appropriateness to PFCs is still being scrutinised as part of the longer DDC development, and partly because they are to be used (in revised form) in the proposed next stage of the "preliminary" monoblock analysis procedure.

For this first stage of procedure development, strict SDC-IC structural rules are only applied to the component deemed as the load supporting component of the monoblock, i.e. the pipe. This is acknowledged to be a simplification; since it can be argued that if the armour or interlayer fail significantly, then this may also cause a failure of the pipe. Recent studies [10][34] suggest that armour failure (such as deep cracking) can be anticipated by analysis of plastic and creep strains in the recrystalised surface layers (if any) of the Tungsten. However, the more complex modelling methods required for such analysis are beyond the scope of the proposed procedure. It is the intention that this limitation will be overcome in the second stage of this work when elasto-plastic methods are used.

\subsection{Thermal rules}

Where it is not possible to apply elastic rules in their full form (due to problems created by residual stress) a simpler temperature rule has been created, for example to avoid temperatures where $\mathrm{CuCrZr}$ is known to be brittle after irradiation. A thermal rule is also created to ensure the heat flux applied to the coolant does not cause film boiling (the critical heat flux rule).

\section{FEA Models}

Two types of model are used initially in this work: an elastic code assessment model, and a full elastoplastic model with residual stress simulation. From these a hybrid model is created combining both elastic and elastoplastic methods as described below.

\subsection{Monoblock geometry, mesh, boundary conditions and materials}

The example design of monoblock used for this work is based on the ITER-like design shown in Figure 2 (similar to that shown in [9] Two planes of symmetry are utilised to enable the use of a quarter model as shown in Figure 3, together with a coupled constraint on the pipe end face to simulate a no bending constraint but allowing axial expansion. To be consistent with elastic code assessment methodology, material properties for both elastic and elasto-plastic models were taken from SDC-IC App. A[17] and are summarised in Table 1. A Chaboche plasticity model was used in the elasto-plastic models, with coefficients (as shown in Table 2) set so that the uniaxial response matches the monotonic and cyclic stress-strain curves provided by the SDC-IC App. A Figure

A.S30.3.1-1 and Figure A.S31.5.8-2 (see example in the Appendix of this paper). Where cyclic stress 
strain data was not available in SDC-IC monotonic curves were used as an approximate substitution to maintain the consistent use of SDC-IC code data. An alternative would be to use the data provided by You et al [23], which shows cyclic curve test data and fitted parameters for both $\mathrm{CuCrZr}$ and $\mathrm{Cu}$.
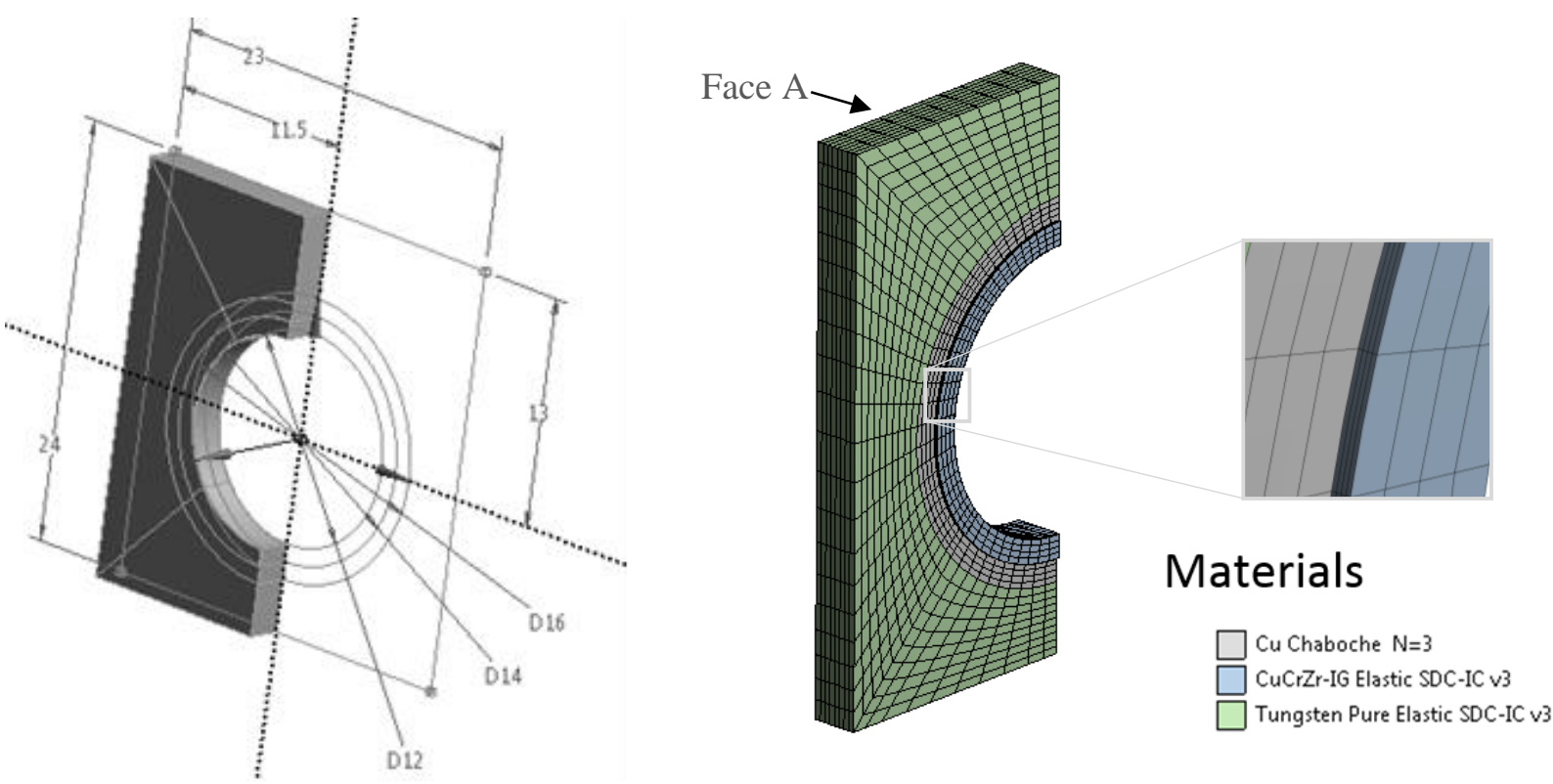

Figure 2 Dimensions of the monoblock and FE mesh used in this study 

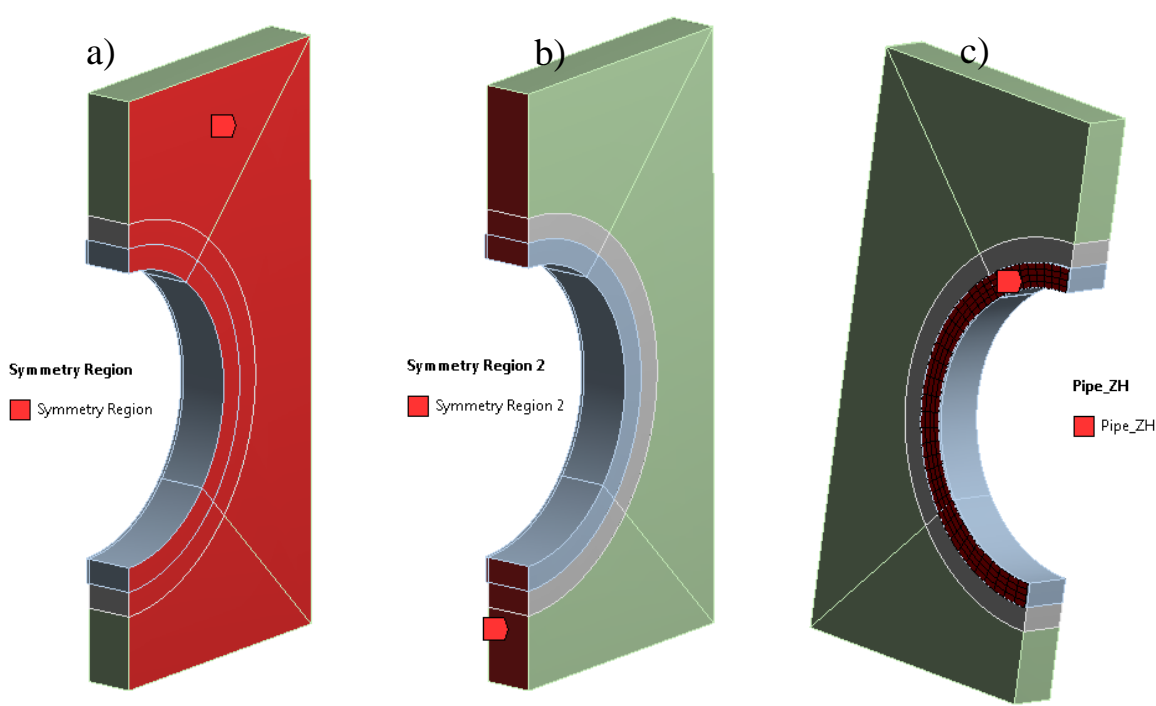

Figure 3 Boundary conditions applied to all models with symmetry conditions $(a, b)$ and coupled constraint on pipe end (c) to simulate a no bending constraint while allowing axial expansion.

Table 1 Summary of properties of considered materials at selected temperatures (taken from[17])

\begin{tabular}{cccccc}
\hline & $\begin{array}{c}\text { Coefficient of } \\
\text { Thermal } \\
\text { Copperature } \\
\left({ }^{\circ} \mathrm{C}\right)\end{array}$ & $\begin{array}{c}\text { Expansion } \\
\left(1 /{ }^{\circ} \mathrm{C}\right)\end{array}$ & $\begin{array}{c}\text { Young's } \\
\text { Modulus } \\
(\mathrm{MPa})\end{array}$ & $\begin{array}{c}\text { Thermal } \\
\text { Conductivity } \\
\left(\mathrm{W} / \mathrm{mm}^{\circ} \mathrm{C}\right)\end{array}$ & $\begin{array}{c}\text { Poisson's } \\
\text { ratio }\end{array}$ \\
\hline \multirow{2}{*}{ Copper } & 150 & $1.68 \mathrm{E}-05$ & 117000 & 0.401 & 0.33 \\
& 300 & $1.74 \mathrm{E}-05$ & 112000 & 0.391 & 0.33 \\
& 400 & $1.82 \mathrm{E}-05$ & 98000 & 0.381 & 0.33 \\
& 20 & $1.67 \mathrm{E}-05$ & 127500 & 0.318 & 0.33 \\
\hline \multirow{5}{*}{ TuCrZr } & 150 & $1.75 \mathrm{E}-05$ & 125000 & 0.339 & 0.33 \\
& 300 & $1.80 \mathrm{E}-05$ & 118000 & 0.346 & 0.33 \\
& 450 & $1.82 \mathrm{E}-05$ & 110000 & 0.347 & 0.33 \\
\hline & 20 & $4.50 \mathrm{E}-06$ & 398000 & 0.173 & 0.28 \\
& 300 & $4.58 \mathrm{E}-06$ & 395000 & 0.133 & 0.28 \\
& 600 & $4.72 \mathrm{E}-06$ & 387000 & 0.127 & 0.28 \\
& 1200 & $4.98 \mathrm{E}-06$ & 356000 & 0.105 & 0.28
\end{tabular}


Table 2 Chaboche model parameter values for Copper and CuCrZr elasto-plastic kinematic hardening model.

\begin{tabular}{|c|c|c|c|c|c|c|c|c|}
\hline & $\begin{array}{c}\text { Temperature } \\
\text { (C) }\end{array}$ & $\begin{array}{l}\text { Yield } \\
\text { Stress } \\
(\mathrm{MPa}) \\
\end{array}$ & $\begin{array}{c}\text { Material } \\
\text { Constant } \\
\mathrm{C} 1 \\
(\mathrm{MPa}) \\
\end{array}$ & $\begin{array}{c}\text { Material } \\
\text { Constant } \\
\gamma 1 \\
\end{array}$ & $\begin{array}{c}\text { Material } \\
\text { Constant } \\
\mathrm{C} 2 \\
(\mathrm{MPa}) \\
\end{array}$ & $\begin{array}{c}\text { Material } \\
\text { Constant } \\
\gamma 2 \\
\end{array}$ & $\begin{array}{c}\text { Material } \\
\text { Constant } \\
\mathrm{C} 3 \\
(\mathrm{MPa}) \\
\end{array}$ & $\begin{array}{c}\text { Material } \\
\text { Constant } \\
\gamma 3 \\
\end{array}$ \\
\hline \multirow{2}{*}{ Copper } & 20 & 45 & 40000 & 7500 & 11000 & 846 & 1000 & 55 \\
\hline & 400 & 18 & 10000 & 4000 & 2500 & 450 & 250 & 55 \\
\hline \multirow{2}{*}{$\mathrm{CuCrZr}$} & 20 & 180 & 300000 & 4000 & 30000 & 825 & 6000 & 45 \\
\hline & 350 & 152 & 200000 & 5000 & 30000 & 1000 & 6000 & 48 \\
\hline
\end{tabular}

\subsection{Simulation methodology}

Two normal operating conditions were considered: "standby" (a uniform $150^{\circ} \mathrm{C}$, i.e the coolant water temperature) and $10 \mathrm{MW} / \mathrm{m}^{2}$ plasma heat load (applied uniformly on face A in Figure 2). These were analysed with steady state thermal and subsequent static structural analysis using ANSYS. Coolant heat transfer coefficients applied to the pipe bore were calculated according to the methods summarised in [12] (based on the work of Sieder Tate [13], Schlosser [14], and Araki et al [15]).

The braze process simulated by the elasto-plastic model is that described by Fursdon [16]. In this, a $1 \mathrm{~mm}$ copper interlayer is first cast onto the bore of the tungsten blocks. These are then brazed onto the $\mathrm{CuCrZr}$ pipe in its solution annealed state, which is then precipitation hardened by subsequent heat treatment for $2 \mathrm{Hr}$ at $470^{\circ} \mathrm{C}$. It is assumed that most of the $\mathrm{CuCrZr}$ residual stress is created during the final hardening cycle, since only then does the $\mathrm{CuCrZr}$ achieved its full strength. In the work described here only the stress created during this full-strength cycle is considered. This gives (in effect) only indicative results, but significantly simplifies the residual stress calculation to a single cooling cycle step; achieved by imposing a uniform room temperature on the monoblock assembly while assigning a stress-free temperature of $470^{\circ} \mathrm{C}$. Since the $\mathrm{CTE}$ of the $\mathrm{CuCrZr}$ is almost four times that of the tungsten, the pipe is caused to contract more than tungsten but is resisted by the tungsten stiffness and strength, giving rise to an expected high tensile residual stress. This is similar to the simulation method described by Li [10] Miskiewicz [11] and You [23].

\section{Analysis Results and discussion}

The results from the elastic model and the elasto plastic model are compared by two methods: comparison of stress value/distribution at each load step, and comparison of stress/strain history throughout all load steps.

\subsection{Stress distribution for the monotonic load case study and absolute stress}

The results of the elasto-plastic simulation of the manufacturing cycle indicates that the residual stress intensity in the pipe component at room temperature (Figure 4a) peaks at $322 \mathrm{MPa}$. This exceeds the material's yield stress, causing plastic strain of at least $0.38 \%$ (Figure 4c). Unlike the localised effects 
normally associated with braze and welds in larger components, for the monoblock the residual stress is calculated to be almost uniform throughout the pipe. As expected the component stresses are tensile with the greatest contribution coming from the hoop stress which is more than 266MPA (Figure 4b).

In the two subsequent operating load steps of the elasto-plastic analysis $\left(150^{\circ} \mathrm{C}\right.$ standby and $10 \mathrm{MW} / \mathrm{m}^{2}$ plasma heating) the peak stress intensity in the pipe reduces to $123 \mathrm{MPA}$ and $240 \mathrm{MPa}$ respectively (Figure 5 a). These values represent the approximate levels of expected peak absolute stress during operations when residual stress is accounted for. As such they are used as the benchmark against which the elastic model is assessed. It is understood that they are lower than the peak residual stress value because, under heating, the material is returning towards the imposed $470^{\circ} \mathrm{C}$ stress-free condition, thus relieving some of the hoop stress.

Results of the elastic analysis of the $150^{\circ} \mathrm{C}$ standby and $10 \mathrm{MW} / \mathrm{m}^{2}$ conditions are shown in (Figure $5 \mathrm{~b}$ and Figure 6b) with peak stress intensities of 288MPa and 613MPa respectively. The hoop stress was found to be compressive, with more than $90 \%$ of the material in the range $-150 \mathrm{MPa}$ to $-440 \mathrm{MPa}$. There is little similarity in either the stress distribution, or the peak stress values, with that expected in the benchmark elasto-plastic simulation with included residual stress effects (shown in Figure $4 \mathrm{a}$ and Figure 5a respectively).

Some disparity is expected between model types because the elasto-plastic model will limit stresses to within yield limits. However, if this was the predominant cause, there should be reasonable correlation for stress in areas below yield, which is not the case. It is suggested most of the disparity comes from the absence of residual stress (from the implied condition in the elastic analysis methodology that initial ambient conditions are stress free). It is not possible to obtain better agreement between the elastic and the elasto-plastic model by applying a non-zero stress-free temperature (as used in the elasto-plastic model). If this is attempted then the resulting peak standby and $10 \mathrm{MW} / \mathrm{m}^{2}$ stress intensities are calculated to be $795 \mathrm{MPa}$ and $1230 \mathrm{MPa}$ respectively, with a similar disparity in overall distribution of stress (as shown by comparison of Figure 5a \& $\mathrm{c}$ and Figure $6 \mathrm{a} \& \mathrm{c})$.

The above results indicate that an elastic model is not capable of accurately calculating expected absolute levels of stress when residual stress exists (at least in the form created in the monoblock manufacture). This means that they cannot be used to make judgement about the structural integrity of a design where monotonic code rules are applied (i.e. for plastic collapse, ductility usage, and fast fracture). 
a)

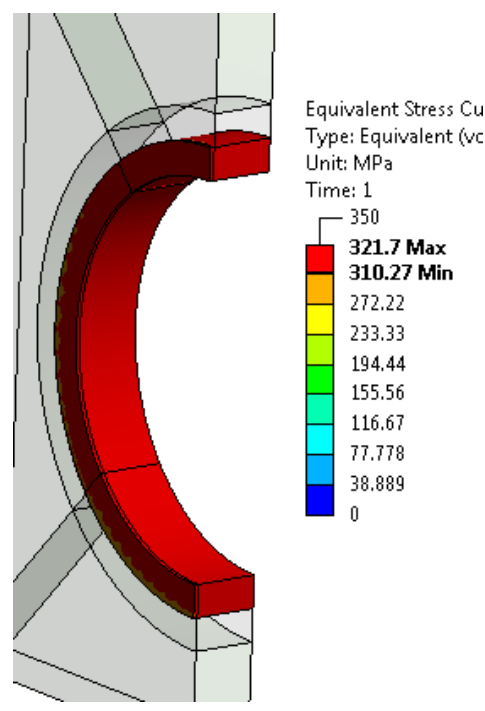

b)

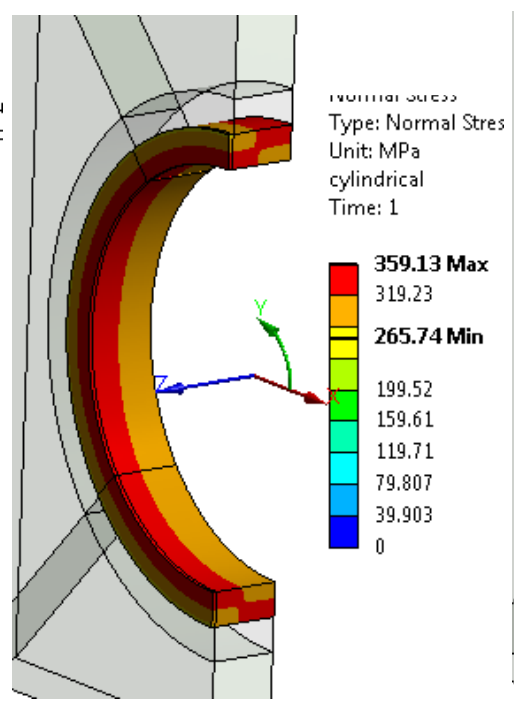

c)

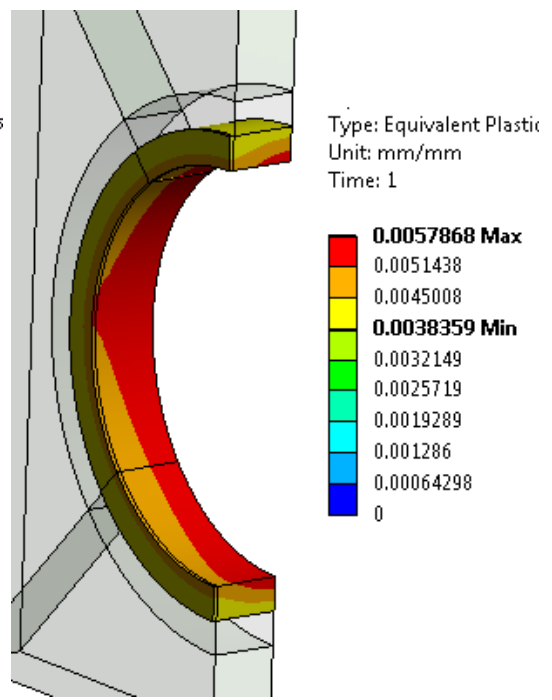

Figure 4 Residual stress condition as calculated by elasto-plastic model show a level of equivalent stress well above yield throughout the pipe material (a) most of which is caused by high hoop stress (b) which results in significant equivalent plastic strain (c).

a)

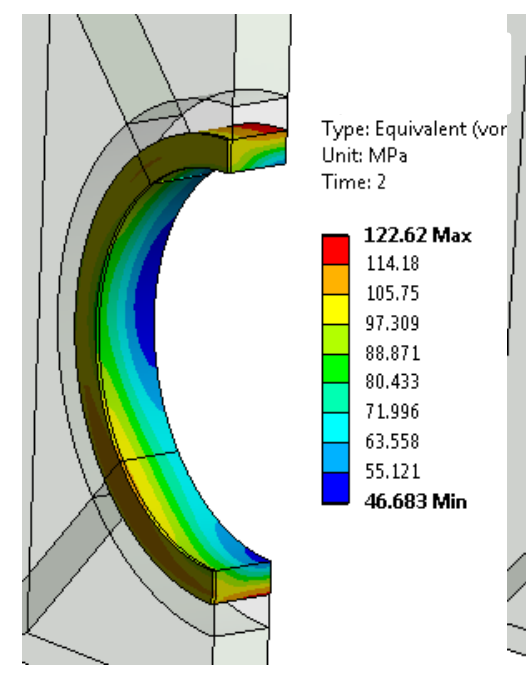

b)

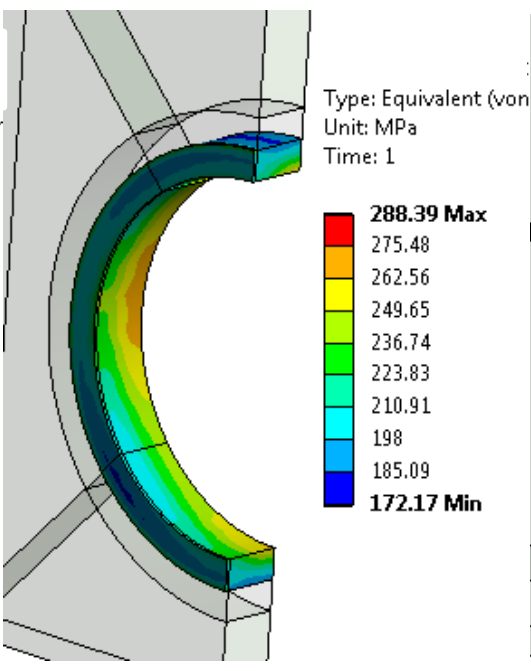

c)

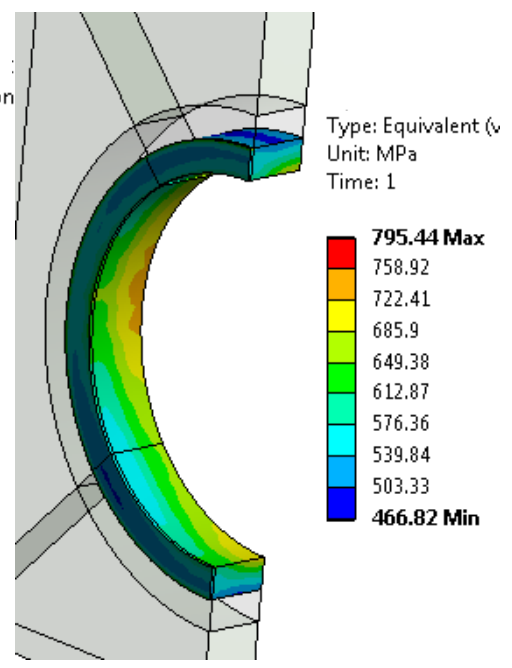

Figure 5 comparison of equivalent stress at standby $150^{\circ} \mathrm{C}$ as calculated by a) the elasto-plastic model (with manufacturing step) b) elastic model ( stress free $=22{ }^{\circ} \mathrm{C}$ ) and c) elastic model (stress free $=470{ }^{\circ} \mathrm{C}$ ), showing that there is little comparison of elastic and the (assumed more accurate) elasto-plastic model irrespective of the stress-free temperature used in the elastic model. 
a)

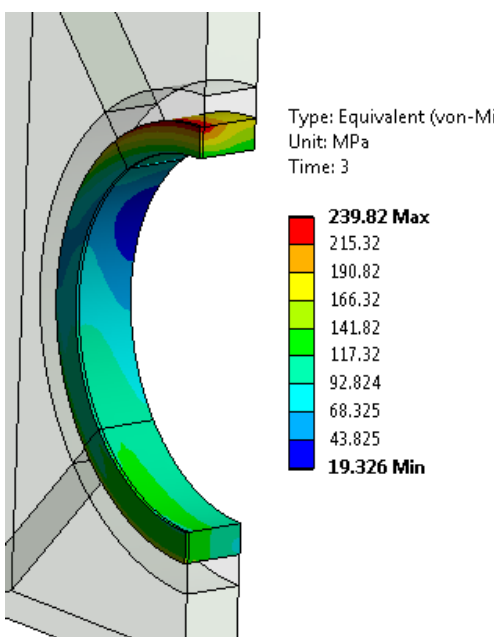

b)

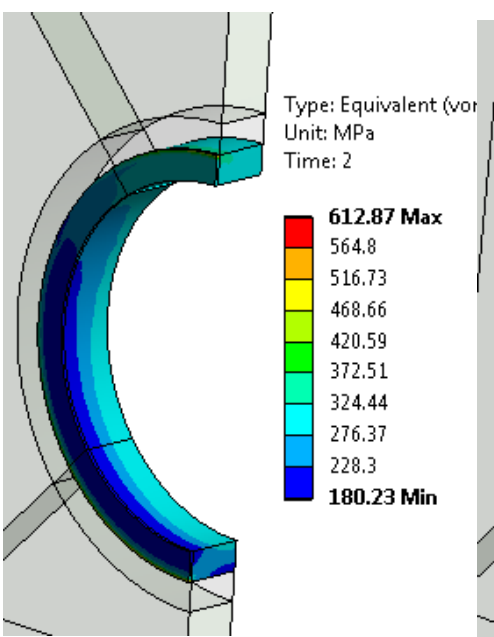

c)

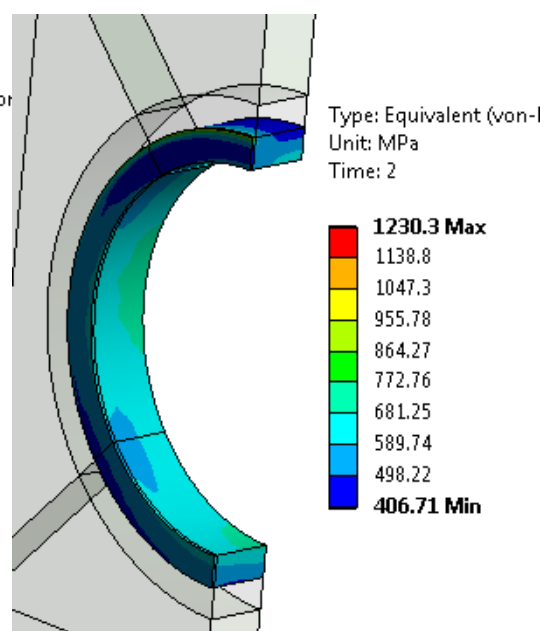

Figure 6 comparison of equivalent stress at $10 \mathrm{MW} / \mathrm{m}^{2}$ as calculated by a) the elasto-plastic model (with manufacturing step) b) elastic model (stress free $=22{ }^{\circ} \mathrm{C}$ ) and c) elastic model (stress free $=470{ }^{\circ} \mathrm{C}$ ). showing again that there is little comparison of elastic and the (assumed more accurate) elasto-plastic model irrespective of the stress-free temperature used in the elastic model.

\subsection{Stress distribution for the cyclic load case study and stress range}

Figure 7 ( $a$ and $b$ ) show the distribution of cyclic stress range (i.e., the difference in stress) calculated when cycling between $22^{\circ} \mathrm{C}$ (shutdown) and the $10 \mathrm{MW} / \mathrm{m}^{2}$ condition for both the elasto-plastic and elastic simulations ${ }^{1}$. This shows a better agreement in the distribution of stress, with areas of low and high stress being roughly similar for both simulations. The peak levels in stress also show better agreement than the absolute stress levels discussed above, but there is still a considerable discrepancy in peak values (379 MPa and $612 \mathrm{MPa}$ respectively). Some of the disparity can again be attributed to the absence of a yield limit in the elastic model as discussed above. However, as above, even in areas where yield stress is not exceeded, stress levels in the elastic model are different to the elasto-plastic model values.

1: Note that these distributions are determined by first calculating at every node a difference tensor by subtracting the tensors from the two load cases. Stress intensity of the resulting difference tensor is then calculated. (it is not the difference of stress intensity values of each load case) 
The difference between the models was partly attributed to the poor simulation of the desired functional properties of the interlayer in the elastic model. This layer is designed to act as a soft buffer layer between the tungsten and the CuCrZr pipe, and it only achieves this function through the process of yielding. In the purely linear elastic model the stress in the copper (Figure 8b) achieves a stress intensity greater than 500MPa. This is far greater than the material's yield stress (and the expected level of stress as displayed by the benchmark elasto-plastic model in Figure 8a) and so results in an unrealistically high level of differential expansion load being transferred from the tungsten to the $\mathrm{CuCrZr}$ pipe.

To demonstrate the significance of this effect, the interlayer material in the elastic model was modified to have elasto-plastic properties (identical to those of the full elasto-plastic model). The results of this hybrid (elastic-elastoplastic) model are shown in Figure $7 \mathrm{c}$ for comparison with those of the full elasto-plastic model in Figure 7a. There is now a close correlation of stress distribution, and close agreement on the peak stress intensities (at 373MPA and 365 MPa respectively). Similar agreement is shown for stress range calculated in cycles from $150^{\circ} \mathrm{C}$ to $10 \mathrm{MW} / \mathrm{m}^{2}$ (as shown in Figure 9a and Figure 9b) and an example stress linearisation (Figure 9c) (as used in a code rule assessment).

The above demonstrates that a model containing an elastically modelled structural pipe element can accurately determine the expected levels of cyclic stress range even when residual stress effects are present (as indicated by the benchmark elasto-plastic model with residual stress simulation) but only if the full model is modified to have an elasto-plastic interlayer. The resulting hybrid model allows elastic cyclic code rules to be applied to the elastically determined cyclic pipe stress values.

a)

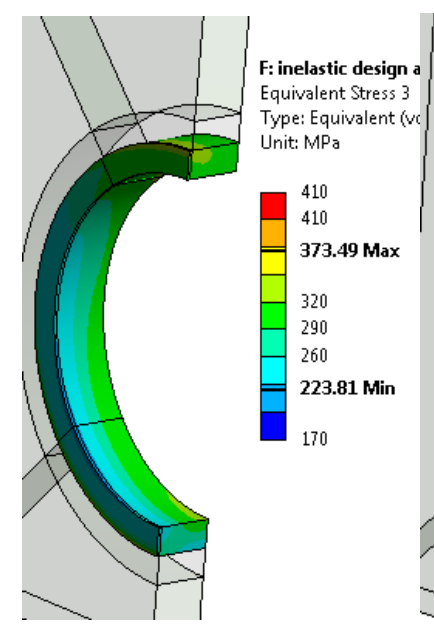

b)

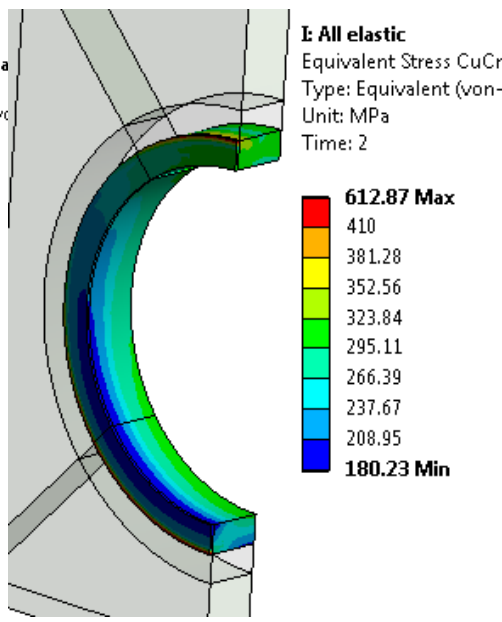

c)

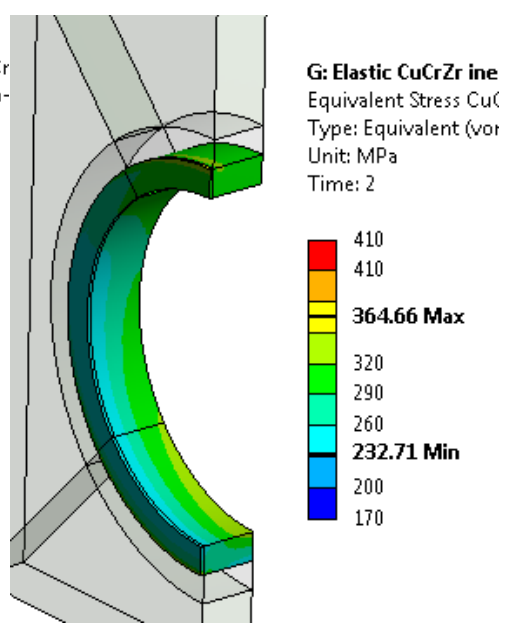

Figure 7 Comparison of calculated equivalent pipe stress-range, between stress at $20^{\circ} \mathrm{C}$ and stress at $10 \mathrm{MW} / \mathrm{m}^{2}$ for a) the elasto-plastic model, b) the all linear-elastic model, and c) the hybrid model (with elastic pipe and elasto-plastic interlayer), showing similar stress distributions with best match to elasto-plastic model (a) achieved using an elasto-plastic interlayer (c). 
a)

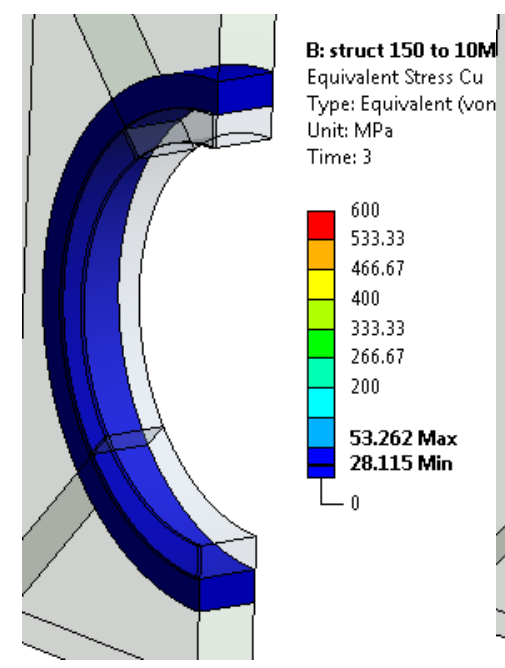

b)

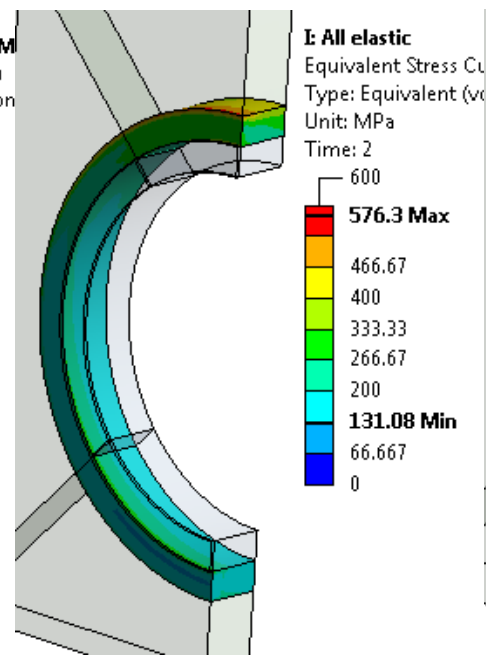

c)

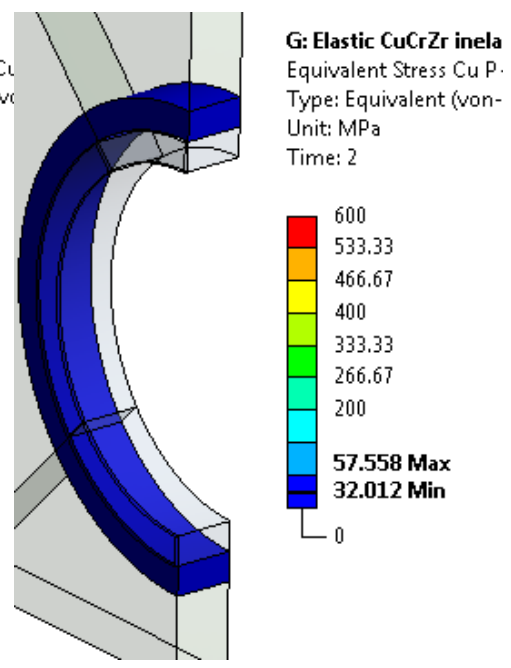

Figure 8 Comparison of equivalent stress levels in the interlayer at $10 \mathrm{MW} / \mathrm{m}^{2}$ heat load for the three model types of a) elasto plastic model b) all linear elastic model and $c$ ) the hybrid model (with elastic pipe and elasto-plastic interlayer), showing that very high levels of stress exist in the all elastic model (b) and as such it does not simulate the desired stress limiting function of a "soft" interlayer (as achieved with the elasto-plastic interlayer simulations in (a) and (c).

a)

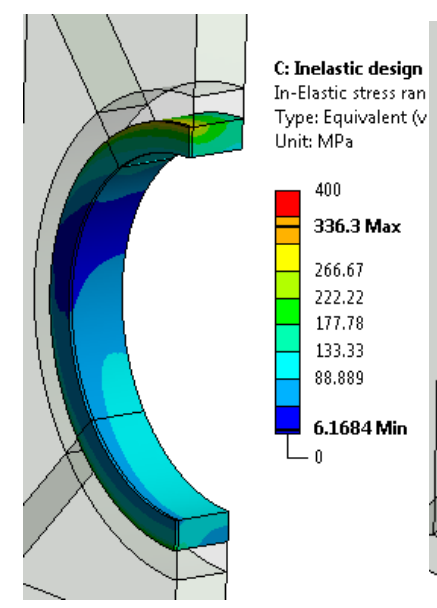

b)

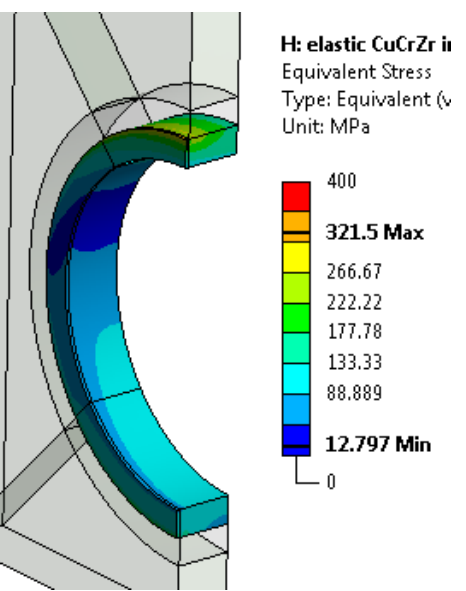

c)

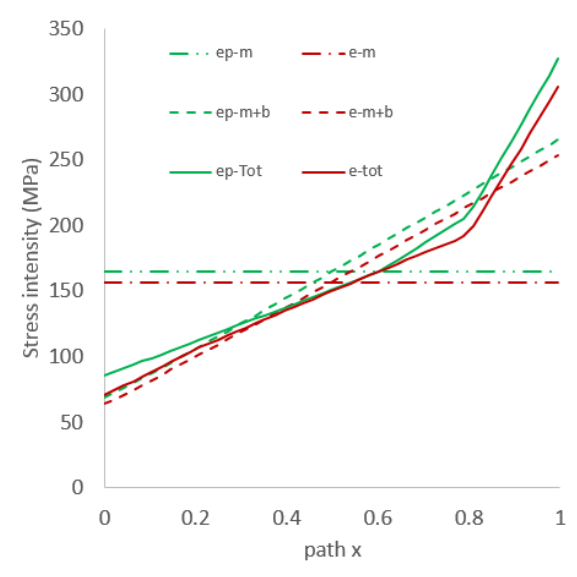

Figure 9 Comparison of calculated equivalent pipe stress-range, between stress at $150^{\circ} \mathrm{C}$ and stress at $10 \mathrm{MW} / \mathrm{m}^{2}$ for a) the elasto-plastic mode and b) the hybrid model (with elastic pipe and elasto-plastic interlayer) illustrating good match in the peak stress, stress distribution, and linearised stress taken in this case at the maximum stress location (elasto-plastic in green, elastic in red, "\#-m" $\rightarrow$ membrane stress “\#-m+b" $\rightarrow$ membrane + bending stress, "\#-tot" $\rightarrow$ total stress).

\subsection{Stress-strain history}

The closer agreement of the results of the hybrid model (elastic pipe and elasto-plastic interlayer) with the benchmark results from the full elasto-plastic model can be explained to some extent by reference to the stress-strain history. Figure 10 shows the stress-strain history at a specific location on the elasto-plastic model as it develops from the stress-free condition at $470^{\circ} \mathrm{C}$, through ambient and $150^{\circ} \mathrm{C}$ standby, to $10 \mathrm{MW} / \mathrm{m}^{2}$. As above, the highest stress is achieved at ambient (residual stress condition), 
with a subsequent relaxation of stress occurring as standby and $10 \mathrm{MW} / \mathrm{m}^{2}$ conditions are applied (as the temperatures return more towards the original stress-free value). The stress-strain history mainly shows that this stress relaxation follows an elastic portion of the elasto-plastic cyclic stress-strain curve, with the result that, during load cycles, both the elastic and elasto-plastic model adopt an elastic response leading to similar range of stress (and strain). The previously observed agreement in stress range distribution (Figure 9) suggests that this is the case over most of the pipe material.

Although both model types display an elastic response under normal operating loads steps, there is a difference between the stress-strain histories because the direction of the stress development is reversed. The elasto-plastic model (with residual stress) has highest stress at ambient and lowest stress in under heat loads but this is vice versa for the elastic model.
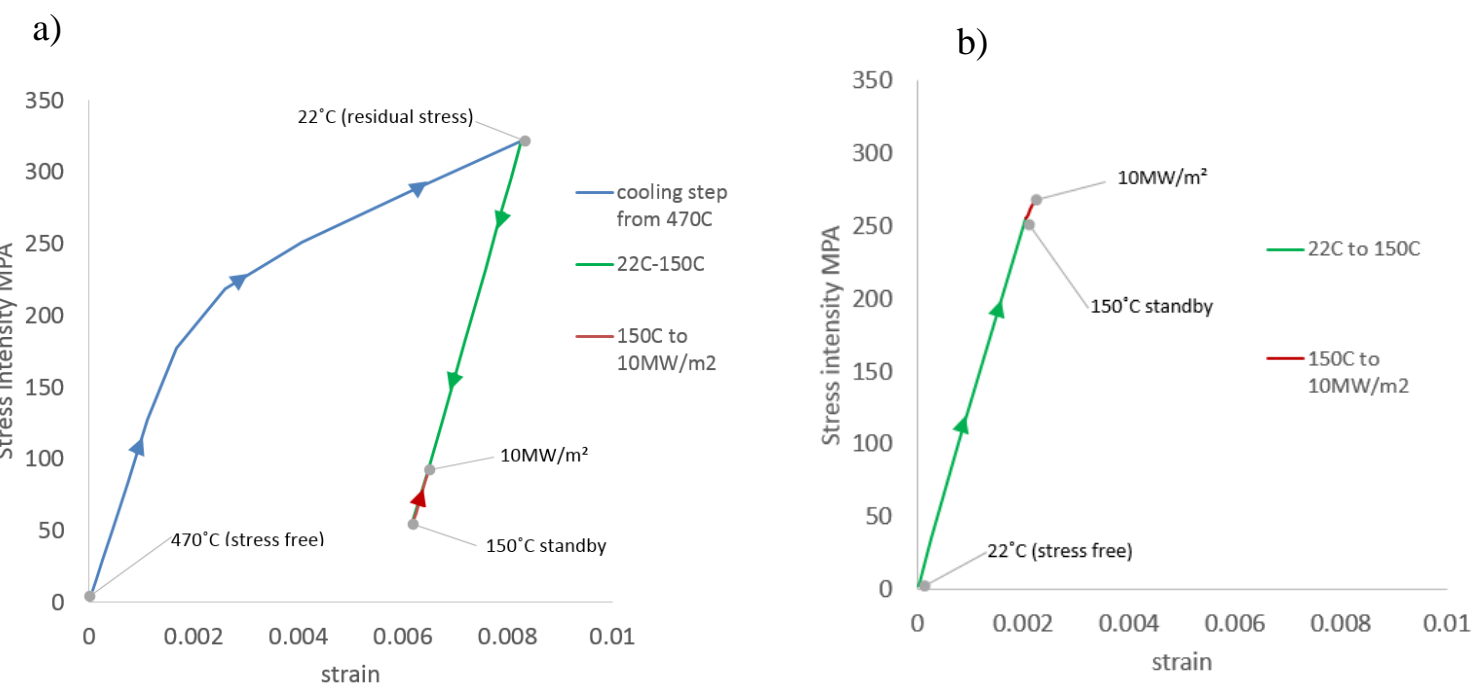

Figure 10 Comparison of stress-strain history at a single location (on the inner diameter of the pipe) showing that according to the elasto-plastic analysis (a) considerable plastic strain and high residual stress is created during manufacture, after which, subsequent heating of normal operating conditions causes a reduction in stress, whereas for the elastic model $(b)$ (which ignores residual stress) normal operating conditions cause increasing stress with considerably higher final stress values. However, for both model types, normal operating conditions fall on an elastic response line. 


\subsection{Other load conditions}

To show some generality of the comparability of the benchmark model and hybrid model, Figure 11 shows calculated peak values of stress intensity range in the $\mathrm{CuCrZr}$ pipe over a range of heat loads for the two model types. Over the range of 5 to $15 \mathrm{MW}$ both models give agreement to within $10 \%$. As the stress approaches the $\mathrm{CuCrZr} 3 \mathrm{Sm}$ limit (elastic range limit) of 300-350 MPa (dependant on temperature) the deviation would be expected to increase, since the elastic model cannot capture expected plastic effects.

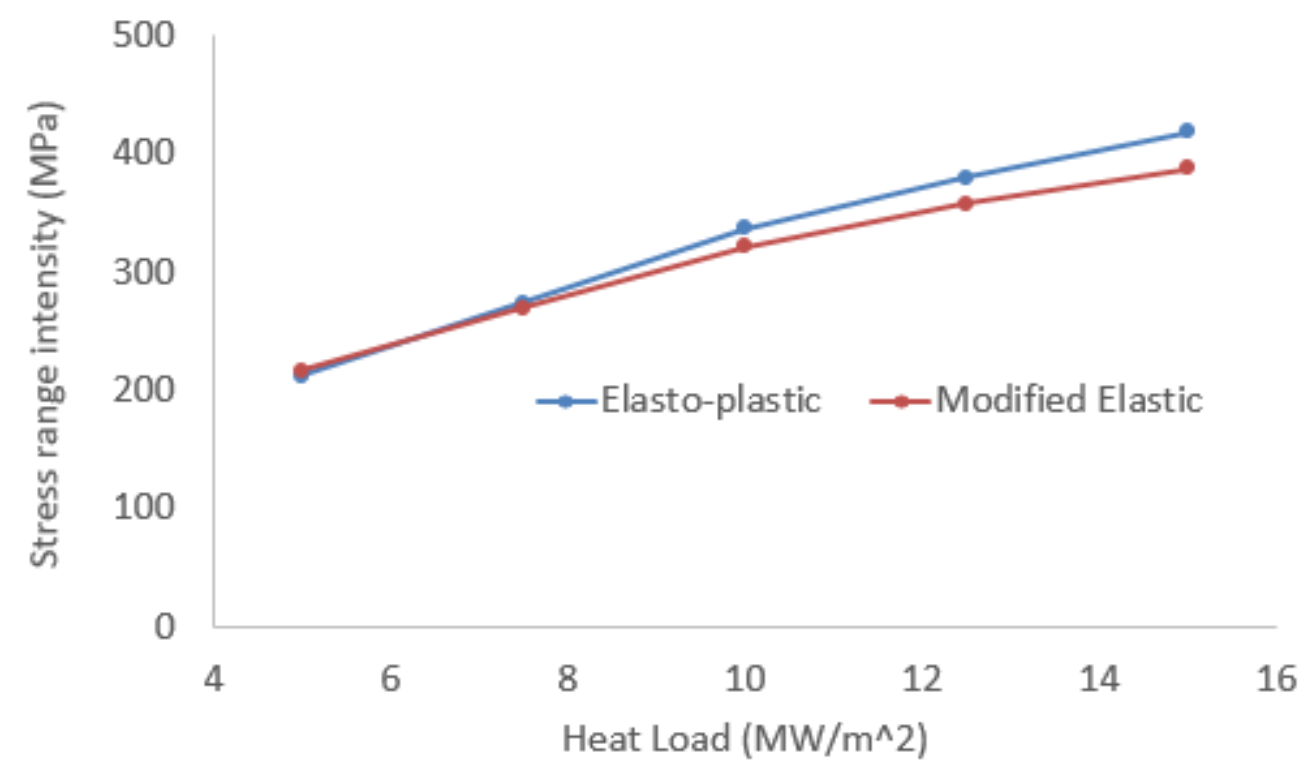

Figure 11: Showing the comparability of the calculated peak intensity of stress range in the CuCrZr pipe for the cycle from standby to plasma heat load using the elasto-plastic model and the hybrid model. Deviations become more apparent when stress range approaches the $\mathrm{CuCrZr} 3 \mathrm{Sm}$ limit (elastic range limit), when the elasto-plastic model will be expected to show include yield effects in the $\mathrm{CuCrZr}$

\section{The Monoblock Elastic Analysis Procedure (MEAP)}

The monoblock elastic analysis procedure was based on the results of the above study. The procedure was formalised into a guideline document listing the recommended modelling method and the assessment rules to apply. The recommended modelling method is essentially as described above using the same quarter model simplification and the same boundary conditions, material definitions and mesh distribution. 
The procedure is termed "elastic" because elastic code rules are applied. However, the finite element model used to determine stress values is not wholly elastic, because it uses the hybrid method discussed above, i.e., with an elastic model of the structural component (the $\mathrm{CuCrZr}$ pipe) and an elasto-plastic (Chaboche) material model for the interlayer. This achieves the desired aim of a finite element model method consistent with the use of elastic assessment rules (the structural element is modelled elastically), while still obtaining accurate results (the loads applied from the interlayer are yield limited). The use of this elasto-plastic material model for the interlayer is further justified by the argument that in the MEAP the interlayer is not subject to the structural rules and so (structurally) serves only the function of applying differential expansion loads from the tungsten.

The results of the modified elastic model created are to be assessed using four rules, described below. These rules are split into structural rules and thermal rules. For the structural rules, following the above observations, only the cyclic rules from SDC-IC are included in their full form. These are the rules for ratchetting and fatigue. For ratchetting, the simpler 3Sm rule (IC 3131.1.2 [2]) is used, since it is not known if the efficiency index diagram rule (IC 3131.1.1 [2]) is still valid for monoblock construction. For fatigue, the rule followed is exactly as stated in SDC-IC IC3132 [2]. For the thermal rules, the main limit to be observed is that the local heat flux applied to the coolant does not cause film boiling. This "critical" heat flux is as defined by the CEA modified Tong - 75 correlation as calculated by the Thermprop program [18]. To capture aspects of the "lost" monotonic rules on allowable strain a simpler temperature rule has been devised as detailed below (although this does not limit the allowed strain within this range). A formal definition of these rules is as follows.

1. Pipe progressive deformation rule (according to SDC-IC 3131.1.2 [2], i.e. the 3Sm rule):

$$
\operatorname{Max}\left(\overline{\mathrm{P}_{\mathrm{L}}+\mathrm{P}_{\mathrm{B}}}\right)+\overline{\Delta \mathrm{Q}} \leq 3 . \mathrm{S}_{\mathrm{m}}
$$

Where:

$\operatorname{Max}\left(\overline{\mathrm{P}_{\mathrm{L}}+\mathrm{P}_{\mathrm{B}}}\right)$ is the worst case local membrane plus bending stress anywhere in the pipe when only primary stress (pressure) is applied. This is determined by linearising the stress intensity along radial through-thickness paths.

$\overline{\Delta Q}$ is the maximum membrane plus bending value of intensity of stress range resulting from thermal loads alone (again, from linearised stress for the same path as the primary load)

Sm is the allowable stress defined in IC 2723 and given in SDC-IC appendix A [17]. 
The linearised bending stress may need to be evaluated at many locations to ensure the worstcase condition is captured. A recommended minimal set of path locations is shown in Figure 12.

2. Pipe fatigue rule (according to IC 3132.2[2]): The total fatigue life usage fraction (V) should be less than one. The required calculation includes

a. the sum of usage fractions for all load cases as defined in IC3132.2[2],

b. the calculation of equivalent strain range for each load case as defined in IC $3132.3[2]$,

c. the use of the fatigue curves given in SDC-IC Appendix A (e.g. A.S31.5.6[17])

3. $\mathrm{CuCrZr}$ temperature rule: The temperature of $\mathrm{CuCrZr}$ pipes should be within the limits of $150^{\circ} \mathrm{C}$ and $300^{\circ} \mathrm{C}$. These bounds are taken from SDC-IC Appendix A Material Data [17] which shows that under irradiation $\mathrm{CuCrZr}$ loses its ductility for temperatures below $150^{\circ} \mathrm{C}$ (Table A.S31.3.5-2) and that excessive creep occurs at temperatures above $300^{\circ} \mathrm{C}$ To avoid too conservative an approach it is proposed that about $25 \%$ of the life should be within the negligible creep limit (Figure 16, A.S2.4.1-1) based on 6000 2hr pulses. [Note: currently there is no guidance for other pipe materials in the MEAP]

4. Pipe wall heat flux rule: The wall heat flux should be less than "critical heat flux" as defined by the CEA modified Tong -75 correlation as sumarised in [12] and the program Thermprop [18]. For example under the conditions of $150^{\circ} \mathrm{C}, 5 \mathrm{MPa}$ and $16 \mathrm{~m} / \mathrm{s}$, the critical heat flux is $44.3 \mathrm{MW} / \mathrm{m}^{2}$. A safety margin of 1.4 is applied.

The following load cases are considered:

1. Plasma heat load at $10 \mathrm{MW} / \mathrm{m}^{2}$,

2. Standby a uniform $150^{\circ} \mathrm{C}$ (the coolant water temperature),

3. Shutdown $=$ uniform $20^{\circ} \mathrm{C}$

Rules 1 and 2 are applied to the stress difference between all possible combinations of the above load cases. These and the expected number of cycles are as follows.

1. Differential stress between standby and plasma heat load (6000 cycles),

2. Differential stress between shutdown and standby (300 cycles),

3. Differential stress between shutdown and plasma heat load (300 cycles)

Although there is no single event that takes the structure directly from shutdown to plasma heat load, the third combination is included in accordance with the rain-flow fatigue cycle counting method ( $T$ Endo [29][30]). A consequence of this method is that excursions from minimum to maximum load conditions are included as a cycle event in themselves and, as such, are considered in addition to the 
intermediate lesser cycles that form most of the cyclic load history. In the MEAP this logic is deemed valid for fatigue and ratchetting cycles.

Two of the above load combinations involve the $20^{\circ} \mathrm{C}$ shutdown condition, a condition which is outside the "allowable" CuCrZr temperature range defined by the pipe temperature rule. This highlights the real concern that once irradiated, the copper $\mathrm{CuCrZr}$ pipe may not have the ductility required to withstand the strains created when cooling the monoblock from standby to ambient. In the MEAP it is assumed some form of regeneration cycle will be used to overcome this issue (for example using bake-out annealing as studied by Fabritsiev [22]), which allows this aspect of the $\mathrm{CuCrZr}$ temperature rule to be ignored for shutdown cycles.

To promote consistency of use, the guideline document describing the MEAP also includes an example application, example calculation spreadsheets, example ANSYS model files and a recommended format for presenting results.

\section{MEAP example assessment results}

The example monoblock analysis given in the MEAP is identical to that used in this paper (using the elastic $\mathrm{CuCrZr}$ pipe and elasto-plastic interlayer) with results for two of the possible three load combinations shown in Figure $7 \mathrm{c}$ and Figure 9b. A summary of the resulting MEAP design assessment is provided below.

Stress results are linearised according to the load paths shown in Figure 12 from which the assessment of rule 1 (the $3 \mathrm{Sm}$ rule) is made, as summarised in Table 3. A summary of the calculation of the fatigue usage fraction (MEAP rule 2) is also provided as shown in Table 4. These and the final assessment of the thermal rules are summarised in Table 5. This shows that for the example case, three of the four MEAP rules are passed (with reserve factor $>1$ ), but there is one marginal fail on rule 1 (the $3 \mathrm{sm}$ rule) which, from Table 3 , can be attributed to excessive stress range occurring in cycles from shutdown to plasma heat load (implying elastic shakedown will not occur increasing the risk of progressive deformation). 
a)

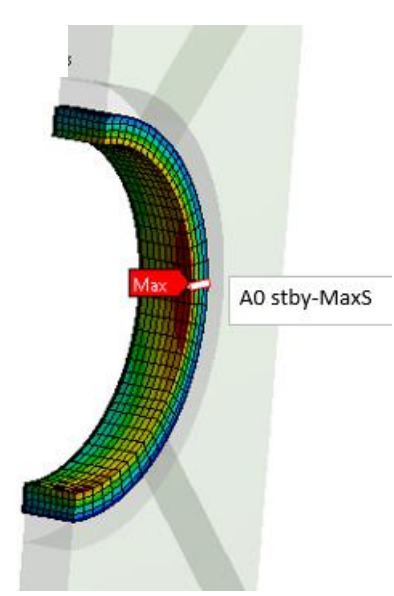

b)

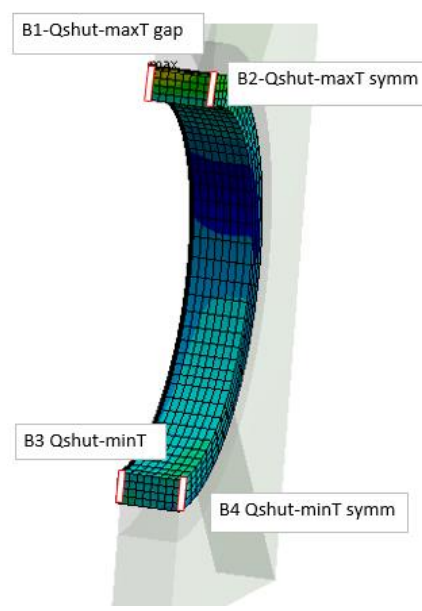

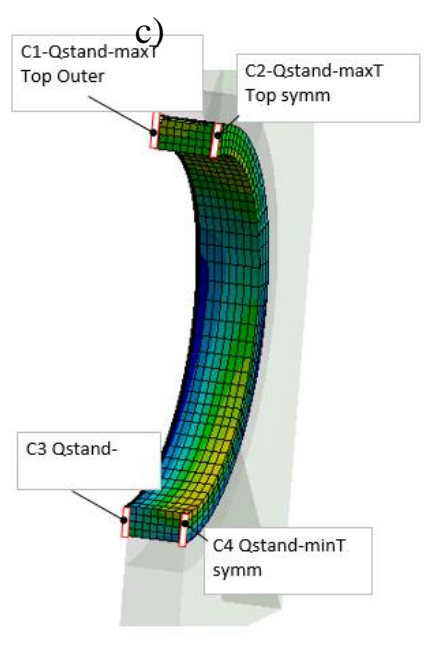

Figure 12 Recommended path locations (and labels) for stress linearisation to obtain worst case membrane plus bending stress values in the three possible load case combinations a) shutdown to standby, $b$ ) shutdown to plasma heat load and c) standby to plasma heat load. 
Table 3 Assessment of MEAP rule 1 (the 3Sm rule) for the 9 recommended linearisation paths shown in Figure 12 under the three load combinations for the example analysis shown in this paper and as provided in the MEAP, resulting in a marginal fail at location "B1" under shutdown to plasma (reserve factor $<1$ ).

\begin{tabular}{|c|c|c|c|c|c|c|c|c|}
\hline \multirow[b]{3}{*}{ load case } & Path & Temp & $3 \mathrm{Sm}$ & $3 \mathrm{Sm}$ & $\mathrm{P}+\mathrm{Q}$ & Reserv Factor & Reserv Factor & \multirow[t]{3}{*}{ comment } \\
\hline & & mean & Un-Irr & irr & & Un-Irr & irr & \\
\hline & & ${ }^{\circ} \mathrm{C}$ & $\mathrm{MPa}$ & $\mathrm{MPa}$ & $\mathrm{MPa}$ & & & \\
\hline $\begin{array}{c}\text { Shut- } \\
\text { standby }\end{array}$ & $\mathrm{A} 0$ & 150 & 351 & N/A & 278 & 1.26 & N/A & $\begin{array}{l}\text { assumed } \\
\text { regenerated }\end{array}$ \\
\hline \multirow{4}{*}{$\begin{array}{c}\text { shut- } \\
\text { PlasmaQ }\end{array}$} & B1 & 262 & 304 & N/A & 321 & 0.95 & N/A & \multirow{4}{*}{$\begin{array}{l}\text { assumed } \\
\text { regenerated }\end{array}$} \\
\hline & B2 & 265 & 303 & $\mathrm{~N} / \mathrm{A}$ & 295 & 1.03 & N/A & \\
\hline & B3 & 153 & 350 & $\mathrm{~N} / \mathrm{A}$ & 301 & 1.16 & N/A & \\
\hline & B4 & 153 & 350 & $\mathrm{~N} / \mathrm{A}$ & 336 & 1.04 & N/A & \\
\hline \multirow{4}{*}{$\begin{array}{l}\text { Standby- } \\
\text { PlasamQ }\end{array}$} & C1 & 262 & 304 & 304 & 268 & 1.13 & 1.13 & \\
\hline & $\mathrm{C} 2$ & 265 & 303 & 303 & 168 & 1.80 & 1.80 & \\
\hline & $\mathrm{C} 3$ & 153 & 350 & 350 & 148 & 2.36 & 2.36 & \\
\hline & C4 & 153 & 350 & 350 & 118 & 2.96 & 2.96 & \\
\hline
\end{tabular}

Table 4 Calculation of the total fatigue usage fraction V (MEAP rule 2) for the combined effects of the three load combinations of the example analysis shown in this paper and as provided in the MEAP (rule is passed with $V<1$ ).

\begin{tabular}{|c|c|c|c|c|c|}
\hline & & $\begin{array}{c}\text { Shutdown to } \\
\text { plasma }\end{array}$ & $\begin{array}{l}\text { Shutdown } \\
\text { to standby }\end{array}$ & $\begin{array}{c}\text { Standby to } \\
\text { plasma } \\
\text { heatload }\end{array}$ & \\
\hline $\mathrm{T}$ & ${ }^{\circ} \mathrm{C}$ & 286.0 & 150.0 & 286.0 & \\
\hline$\Delta(P+Q+F)$ & Mpa & 364.0 & 280.0 & 336.0 & \\
\hline $\mathrm{E}$ & $\mathrm{MPa}$ & 1.17E+05 & $1.23 \mathrm{E}+05$ & 1.17E+05 & \\
\hline e1 & $\%$ & 0.2768 & 0.2018 & 0.2555 & \\
\hline neuber $\mathrm{K}$ & $\mathrm{MPa}$ & 100.77 & 56.51 & 85.86 & \\
\hline e3 & $\%$ & 0.29 & 0.21 & 0.27 & \\
\hline kv & - & 1.181 & 1.079 & 1.160 & \\
\hline e4 & $\%$ & 0.0501 & 0.0160 & 0.0408 & \\
\hline eTot & $\%$ & 0.34 & 0.23 & 0.31 & \\
\hline $\mathrm{N}$ & cycles & $6.8 \mathrm{E}+03$ & $3.7 E+04$ & $9.8 \mathrm{E}+03$ & \\
\hline requirement & cycles & 300.00 & 300.00 & 6000.00 & Total Usage \\
\hline Usage V & - & 0.04 & 0.01 & 0.61 & 0.66 \\
\hline
\end{tabular}

Table 5 Overall summary of a MEAP assessment of the example monoblock design used in this paper and the MEAP guideline document showing in this case that the design passes three of the four rules with a reserve factor $>1$. There is a marginal fail on Rule 1(the 3 Sm rule).

\begin{tabular}{|l|l|c|l|}
\cline { 3 - 4 } \multicolumn{2}{c|}{} & $\begin{array}{c}\text { Min Reserve } \\
\text { factor }\end{array}$ & \multicolumn{1}{c|}{ Comment } \\
\hline Rule 1 & Max $\left(P+P_{\diamond}\right)+\overline{\Delta Q} \leq 3 . S_{m}$ & 0.95 & fails on cycles to shutdown \\
\hline Rule 2 & Fatigue & 1.64 & \\
\hline Rule 3 & Pipe material temperature range & 1.04 & just meets max criterion \\
\hline Rule 4 & Critical wall heat flux & 2.88 & lowest reserve factor on wall temperature \\
\hline
\end{tabular}




\section{Discussion}

The hybrid model employed in the MEAP shows the ability to capture the cyclic stress range of the more complex elastoplastic model allowing elastic code rules to be applied. To be more precise the stress range calculated is comparable only if elastic shakedown occurs. Nonetheless, this satisfies the needs of a code assessment model which needs only to accurately detect stress up to and including the 3Sm (elastic range) limit being assessed. The MEAP model does not claim to predict stress range accurately beyond these limits since it does not capture the effects of yield in the pipe component. However, since the $3 \mathrm{Sm}$ limit is based only on the linearised bending plus membrane stress, it is possible, at the limits of $3 \mathrm{Sm}$, for the peak stress to exceed the elastic stress range creating plastic strain not captured by an elastic model. Design codes such as SDC-IC, and the MEAP recognise this, and use a plastic strain estimation method to correct this "error" as summarised by SDC-IC appendix $\mathrm{B}$ [28] section B 3323 ("Calculation of equivalent strain range $\Delta \mathrm{e}$ ") using, among others, Neuber curve correction factors. This is captured by MEAP rule 2 clause $b$ in section 5 above.

A disadvantage of the use the $3 \mathrm{Sm}$ ratchetting rule in the MEAP is that it leads to a potentially overly conservative design since it does not allow the possibility of stable cyclic plasticity (low cycle fatigue). This becomes particularly relevant when consideration is given to the slow transient load case where heat loads of the order $20 \mathrm{MW} / \mathrm{m}^{2}$ are expected. It has been shown by Bree [26] that circumstances can exist where stresses do exceed the elastic shakedown (3Sm) condition without ratchetting occurring (i.e. the stable cyclic plasticity condition), and these have been incorporated into existing design codes using Bree diagrams and the associated Stress Ratio methods discussed in the introduction. However, the Bree diagram only applies to thin walled pressure vessels (including tubes etc), and even then, only for one type of load cycling [27]. To understand the nature of ratchetting under cyclic plasticity conditions in a full monoblock assembly, one could study the elastoplastic response of the assembly and employ the same methodology exemplified by Bree on thin walled pressure vessels (perhaps even to produce a monoblock-Bree diagram, to support elastic analysis methods). However, it is suggested that a more practical approach is to adopt the full elastoplastic methods shown by Li and You [10,24,25], where global ratcheting and low cycle fatigue in monoblock assemblies is assessed by direct observations of plastic strain history over a number of cycles. It is concluded therefore that a true assessment of stable cyclic plasticity in the relatively complex geometry of the monoblock assembly cannot be assessed without modelling methods beyond those used in elastic design code. For the purposes of EURO-fusion concept design development, assessment of ratchetting is made at the normal $10 \mathrm{MW} / \mathrm{m}^{2}$ heat load condition using the $3 \mathrm{SM}$ rule, with an assumption that passing this conservative rule at the lower heat load gives the best indicator of performance at the higher slow transient heat load when elastic rules are used. This is clearly a weakness of the elastic design rule approach and this is one of the reasons why EUROfusion are supporting the development of the Demo Design Criterion using elastoplastic methods. 


\section{Conclusions}

1. A simplified simulation of the manufacturing cycle of a typical monoblock design using elastoplastic modelling methods has shown that significant through thickness residual stress can be expected in the structural pipe component resulting from the differential contraction of the tungsten armour and $\mathrm{CuCrZr}$ pipe.

2. There is almost no correlation between the absolute pipe stress (magnitude and distribution) calculated by a purely elastic model (as used in design code assessment) and that calculated with an elastoplastic model which includes this residual stress effect. Assuming the elasto-plastic simulation provides a more accurate (benchmark) indication of the real state of stress, this suggest that any design assessment using absolute stress and the conventional elastic analysis method would be incorrect.

3. However, for the normal operation $10 \mathrm{MW} / \mathrm{m}^{2}$ heat load case considered, there is a better correlation between the two model types when comparing cyclic stress range (the differential stress when cyclic between two load cases). Furthermore, an almost exact agreement can be achieved (+-5\%) if the copper interlayer of the elastic code assessment model is simulated using elasto-plastic properties (to form a hybrid model)

4. This hybrid modelling method achieves the desired aim of the use of elastic finite element modelling of the structural component that is consistent with the use of elastic assessment rules, while obtaining accurate simulation of the yield limited tungsten/CuCrZr differential thermal-expansion loads applied through the non-structural interlayer.

5. The modelling method thus enables the valid application of SDC-IC cyclic elastic design code rules (for fatigue and ratcheting) on the monoblock structural pipe component. It has been used to create a recommended analysis procedure for assessing the various designs of monoblock now being developed for EUROfusion.

\section{Further work}

The MEAP will be superseded by a procedure based on a fully elasto-plastic finite element modelling method similar to that described for the benchmark model above and the work of Li and You [10][24] [25]. From this, rules for assessing the design performance using the elasto-plastic methods are to be developed; rules which it is intended can be applied to all components within the monoblock assembly and that are devised specifically to overcome the problems associated with all plasma facing components resulting from multi-material assemblies with different CTEs and different yield strengths. These will be amalgamated into the rules being developed for the DEMO design criteria [8]. 


\section{References}

[1] You J-H et al European DEMO divertor target: Operational requirements and material-design interface. Nuclear Materials and Energy 9 (2016) 171-176

[2] ITER design code, In-vessel Components, _SDC-IC_222RHC_v3_0

[3] ASME Boiler and Pressure Vessel Code (BPVC) 2013 Section VIII, Rules for Construction of Pressure Vessels, Division 1

[4] RCC-MR 2007 Design and construction rules for mechanical components of nuclear installations

[5] Porton et al. Structural integrity for DEMO: An opportunity to close the gap from materials science to engineering needs. Fusion Engineering and Design 109-111 (2016) 1247-1255

[6] T. Hirai et al. Use of tungsten material for the ITER divertor. Nuclear Materials and Energy 9 (2016) 616-622

[7] M. Kalsey and M Porton. Developing Structural Design Criteria for Fusion Reactor In-Vessel Components 2014 22nd International Conference on Nuclear Engineering. ICONE22-31216, pp. V006T14A008

[8] M Gorley, M Fursdon, M Kalsey. Integrating Materials Engineering and Design for Fusion, 27th IEEE Symposium on Fusion Engineering. Shanghai 2017. Submitted for publication IEEE transactions.

[9] F. Crescenzi, et al "Design study of ITER-like divertor target for DEMO," Fusion Eng. Des., vol. 98-99, pp. 1263-1266, 2015

[10] M Li, J-H You. Interpretation of the deep cracking phenomenon of tungsten monoblock targets observed in high-heat-flux fatigue tests at $20 \mathrm{MW} / \mathrm{m}^{2}$. Fusion Engineering and Design 101 (2015) $1-8$

[11] M. Miskiewicz, J.-H. You "Impact of plastic softening of over-aged CuCrZr alloy heat sink tube on the structural reliability of a plasma-facing component”. Fusion Engineering and Design 83 (2008) 66-71

[12] T D Marshall et al. Modelling the Nukiyama curve for water-cooled fusion divertor channels Fusion Technology 39(2) · March 2001

[13] E. N. Sieder and G. E. Tate, "Heat Transfer and Pressure Drop of Liquids in Tubes," Industrial and Engineering Chemistry, 28, 12, pgs. 1429-1435 (1936)

[14] J. Schlosser, Design Task (D 67) - Update of EC Thermal Hydraulic Database: Thermal hydraulic Correlations for ITER

[15] M. Araki, M. Ogawa, T. Kunugi, S. Ikeda, K. Satoh, and S. Suzuki, "Experiment on Heat Transfer of Smooth and Swirl Tubes Under One-Sided Heating Conditions," International Journal of Heat and Mass Transfer, 39, 14, pgs. 3045-3055 (1996). 
[16] Fursdon, M., et al. The development and testing of the thermal break divertor monoblock target design delivering $20 \mathrm{MW} / \mathrm{m}^{2}$ heat load capability. 16th International Conference on Plasma-Facing Materials and Components for Fusion Applications (PFMC-16). Neuss. 2017-0516 - 2017-05-19. Submitted for publication in Physica Scripta.

[17] SDC-IC appendix A, _Materials_Design_Limit_Data_222RLN_v3_2[1].pdf (201)

[18] Thermprop 5.2 “A thermohydraulic properties program for heat transfer design evaluations based on the eupiter code version 4.2. Users Guide Udo W Mszanowski @ EFDA June 2006

[19] SDC-IC appendix A- Appendix,__ G 74 MA 8 01-05-28 W0.2 (2003)

[20] S. A. Fabritsiev \& A. S. Pokrovsky, Plasma Devices and Operations, 11 (No.4) (2003) 297307.

[21] Fabritsiev S.A. and Pokrovsky A.S. 2005 Effect of high doses of neutron irradiation on physico-mechanical properties of copper alloys for ITER applications Fusion Eng. Des. 73 19-34

[22] S.A. Fabritsiev, A.S. Pokrovsky, Effect of bake-out regime on the recovery of properties of copper based alloys and copper/steel joints, J. Nucl. Mater. 307-311 (2002) 431-442.

[23] J. H. You, M. Miskiewicz, "Material parameters of copper and $\mathrm{CuCrZr}$ alloy for cyclic plasticity at elevated temperatures", J. Nucl. Mater. 373 (2008) 269-274

[24] M. Li, E. Werner, J.H. You. "Low cycle fatigue behavior of ITER-like divertor target under DEMO-relevant operation conditions" Fusion Engineering and Design 90 (2015) 88-96.

[25] Ch. Linsmeier, M. Rieth, J. Aktaa,T. Chikada, A. Hoffmann, J. Hoffmann, A. Houben, H. Kurishita, X.Z. Jin, M. Li, A. Litnovsky, S.T. Matsuo, A. von Müller, V. Nikolic, T. Palacios, R. Pippan, D. Qu, J. Reiser, J. Riesch, T. Shikama, R. Stieglitz, Th. Weber, S. Wurster, J.H. You, Z. Zhou "Development of advanced high heat flux and plasma-facing material". Nuclear Fusion 57 (2017) 092007 (60pp).

[26] J. Bree Elastic-plastic behaviour of thin tubes subjected to internal pressure and intermittent high-heat fluxes with application to fast-nuclear-reactor fuel elements. Journal of strain analysis, vol2 no 31967.

[27] D. N. Moreton \& H. W. Ng, "The extension and verification of the Bree diagram", Structural Mechanics in Reactor technology, Vol L, 1981.

[28] SDC-IC Appendix_B,_Guidelines_for_Analysis,_In-_222RM6_v3_1

[29] "The Rainflow Method in Fatigue", The Tatsuo Endo Memorial Volume, Edited by:Y.

Murakami, ISBN: 978-0-7506-0504-5

[30] M Matsuishi, T Endo, "Fatigue of metals subjected to varying stress". Japan society of mechanical engineers, Furuoka, Japan, March 1968.

[31] Changjun Lia et al, "Theoretical analysis on the damages for tungsten plasma facing surface under superposition of steady-state and transient heat loads" Fusion Engineering and Design 132 (2018) 99-106 
[32] R.A. Pitts et al, "A full tungsten divertor for ITER: Physics issues and design status”, Journal of Nuclear Materials 438 (2013) S48-S56

[33] Ch. Linsmeier et al, "Development of advanced high heat flux and plasma-facing materials", Nucl. Fusion 57 (2017) 092007,

[34] Muyuan Li, Jeong-Ha You, "Structural impact of creep in tungsten monoblock divertor target at $20 \mathrm{MW} / \mathrm{m}^{2} "$, Nuclear Materials and Energy 14 (2018) 1-7

\section{Acknowledgements}

This work has been carried out within the framework of the EUROfusion Consortium and has received funding from the Euratom research and training programme 2014-2018 under grant agreement No 633053 and from the RCUK Energy Programme [grant number EP/I501045]. To obtain further information on the data and models underlying this paper please contact PublicationsManager@ccfe.ac.uk*. The views and opinions expressed herein do not necessarily reflect those of the European Commission.

Appendix - Chaboche model fit to cyclic stress-strain curves

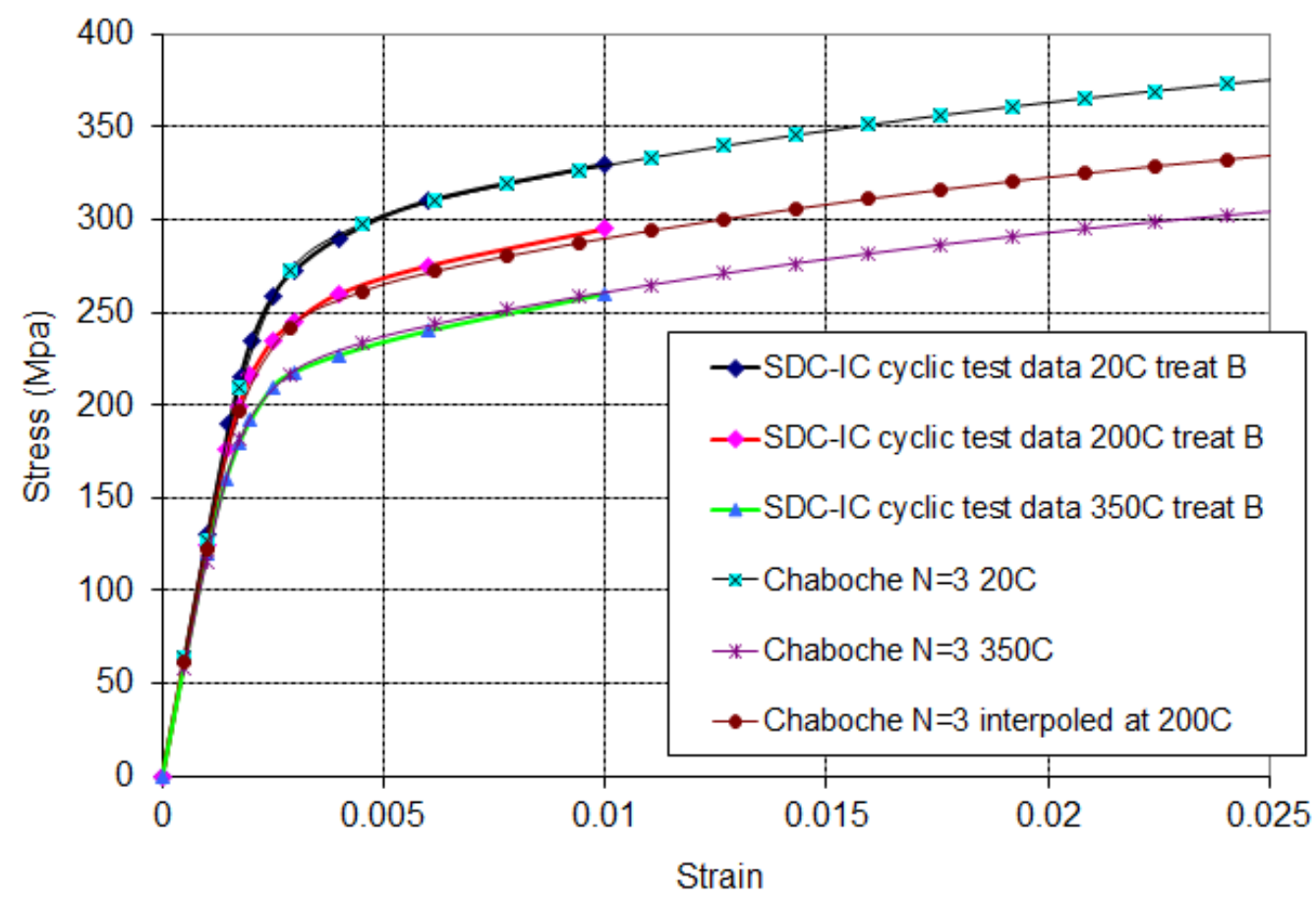

Figure Al CuCrZr Chaboche material model fit to SDC-IC uniaxial cyclic stress-strain curves (Ref Fig A.S31.5.8-[2]) 